\title{
Children Living in Poverty: Exploring and Understanding Its Developmental Impact
}

\author{
Sadguna Anasuri, Ph.D., CFLE \\ Department of Family and Consumer Sciences \\ College of Agricultural, Life, and Natural Sciences \\ Alabama A\&M University, United States
}

\begin{abstract}
Living in impoverished environmental conditions can vastly impact children-in their physical, cognitive, social, and emotional developments. Past research has mainly focused on the physical development and access to good quality educational resources, etc. Recently, more light has been shed on broader and complex impact of immediate and surrounding environments on the overall development of children. The current article will examine recent research on the influence of various factors-demographic (parental education, work, ethnicity, marital status), individual (family stress), relational (parenting, conflict), institutional (low-quality classrooms, neighborhood), and their impact on child's physical, emotional, and behavioral health, cognitive performance-learning, language, and achievement. Additionally, family stress model and parental investment models are examined for their significance in understanding childhood poverty. Role of resilience during such economic and social hardship, and its influence on the overall success of children during their growing years, and in later life was reviewed for their connections and relevance. The context of poverty is illustrated using various theoretical perspectives for further interpretations and understanding.
\end{abstract}

Key words: children, development, environment, impact, poverty.

\section{INTRODUCTION}

Can you estimate how much of the nation's future health will be determined by the 2,500 babies who were born into poverty today (Kindig, 2015)? According to Children's Defense Fund (CDF), every day in the United States, 2,500 babies are born into poverty, 1,267 babies are born into extreme poverty, 65 babies die before their first birthdays, 870 babies are born at low birth weight, and 1,837 children are confirmed as abused or neglected. Overall, according to epidemiologic and sociologic evidence, poverty has increased the risk of death by $75 \%$ for those aged $25-64$ and by $40 \%$ for those over the age of 65 . It was further found that in the United States, over $20 \%$ of children under the age of 18 are officially poor (Yoshikawa, Aber, \& Beardslee, 2012). Poverty is one of the oldest and yet unresolved issues in the history of welfare (Butiu, 2014; Gradin \& Canto, 2012). According to Butiu (2014), the majority of social policies define poverty as either a lack of income or insufficiency of consumption. Poverty is a national economic crisis that affects the lives of many individuals today. Poverty in childhood has long been recognized as a determinant of a wide variety of negative outcomes especially, from lower educational achievement and behavioral problems to lower earnings in the labor market. Poverty in childhood is linked with several outcomes of development, but more specifically, socio-emotional, physical, and cognitive (Borjas, 2010).

Living in poverty presents a chronically stressful context and places demands on an individual's stress response system (Zakewski et al., 2012). Kindig (2015) found that poverty affects health through several biological pathways and often begins early in life. Evidently, physical activity and good nutrition are important to wellbeing, but social and environmental factors have an equal or greater impact on development. Poverty and lack of education have been confirmed to have a direct biological impact on health through neuroendocrine and immunologic system stress pathways. These biologic pathways function throughout the life span, but growing evidence points to early life as a particularly vulnerable period. Adverse early-childhood events and even prenatal experiences have been proven to affect long-term health, educational attainment, and eventually economic productivity over a lifetime.

Children in poverty today are at a greater risk. Broadly defined, risk is presumed to be a specific event that provokes a given reaction to children (Crivello \& Boyden, 2014). Popular images of children that are considerably "at risk" illustrate a large amount of circumstances such as: children exposed to physical trauma, severe poverty, and orphanhood, just to name a few. Risk consists of negative connotations and according to Crivello and Boyden, is thought to pose an inevitable threat to children with the undesirable outcomes such as immediate and later maladjustment. 
How each child responds to poverty is dependent upon variables such as level of resiliency, gender, age, available resources, support, living circumstance, etc. (Grineski, 2014). As a result of how the child responds, some successfully overcome the challenges while others unfortunately do not. For example, low school attainment and teen parenting both increase adolescent change of raising children in poverty (Yoshikawa, et al, 2012). In addition, education, achievement and family structure in one generation can therefore be determinants of family income poverty and then child health and overall development in the next generation. Similarly, distressed neighborhoods, low-performing schools, less nutritious food supplies, etc. are exposures to poverty-related risks and can be seen as rival explanations for the association between poverty and children's health and development. In sum, poverty is intertwined with a large number of co-factors that can produce a varying degree of impacts singly and/or collectively.

Poverty has many effects on children; however those effects are broken down into two broad categories consisting of direct effects and mediated effects (Yoshikawa, et al, 2012). When attempting to explain the impact and effects that poverty has on children, there are factors that one needs consider (See Fig. 1). Factors that are predictors of family poverty are parent education, parent marital status, parent work status, job prestige, race, ethnicity, and documentation status. Furthermore, these factors can be broken down into three sections consisting of dimensions of poverty, mediating mechanisms, and child outcomes. There are dimensions of poverty into which these factors can be delineated. Firstly, the dimensions consist of low family income (absolute poverty) and other dimensions of poverty consisting of material hardship, relative poverty, asset poverty and social exclusion. Secondly, the mediating mechanisms section is broken down into three components consisting of institutional aspects (low quality classrooms/schools, low job quality, high job instability, neighborhood danger, lack of resources, collective efficacy, and health care access); relational aspects (parent/child security, adult and parent/child, relational conflict and parenting behaviors); individual aspects (parenting stress, parental M-E-B stress, parent neurophysiology, child stress, child behavior and child neurophysiology). Lastly, the child outcomes section is subdivided into three components regarding health, these components consist of physical health and development, mental emotional and behavioral health, and cognitive and language development/learning achievement.

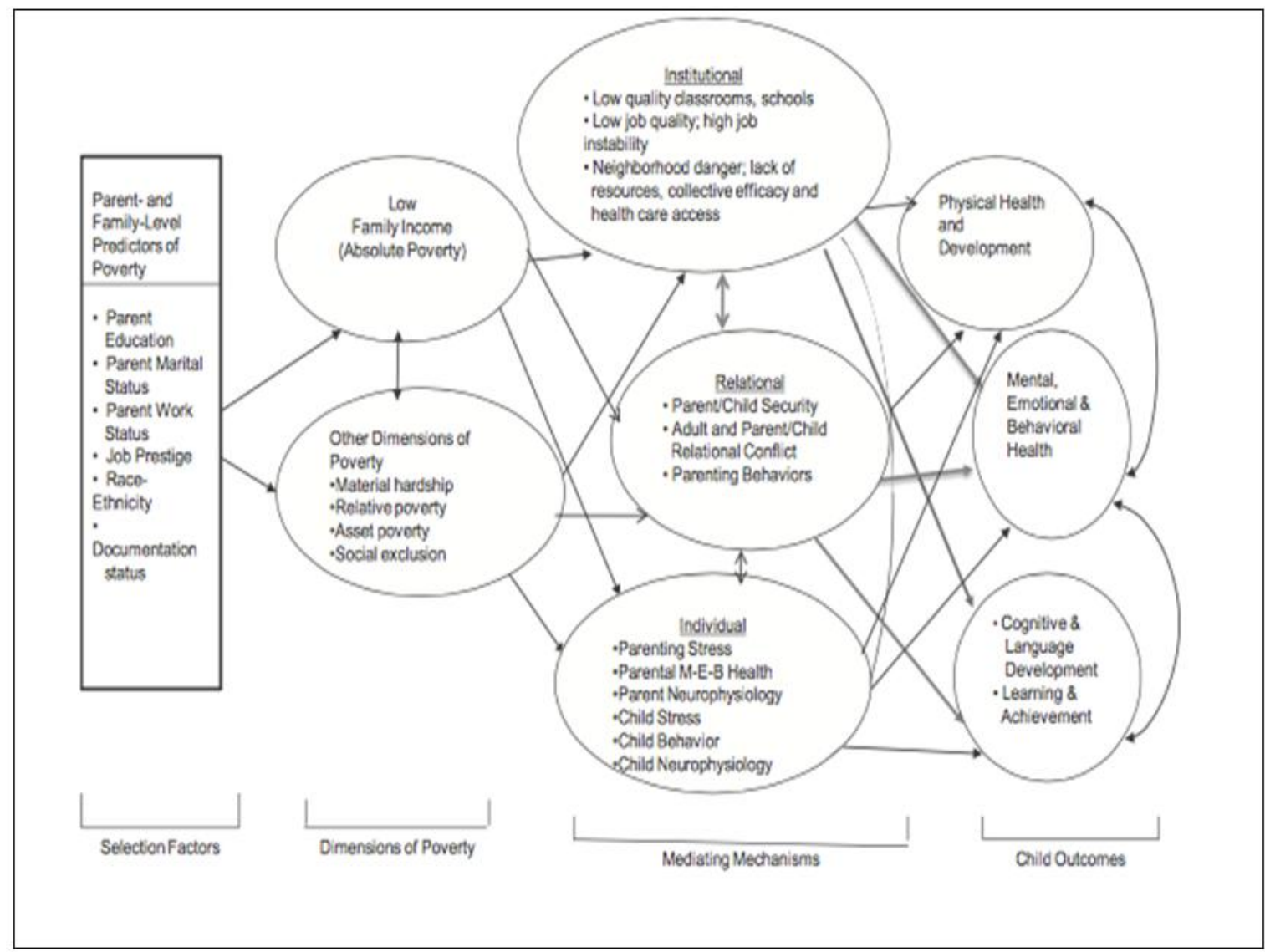

Figure 1. Direct and Mediated Effects of Poverty

(Diagram source: Yoshikawa, Aber, \& Beardslee, 2012) 


\section{FACTORS SURROUNDING CHILDHOOD POVERTY}

The main clusters of factors that determine the poverty of children can be categorized into three groups: (1) demographic and family profile (parent's age, parents' education level, the number of children in the family and family's structure); (2) labor market (parents' employment status and their income); (3) organizational policy (measured by financial transfers in household with children) (Chen \& Corak, 2008). The methods for determining poverty are crucial and hence are a constant source of debate and undergo frequent changes throughout research (Butiu, 2014). This is because the results obtained often become warning signs and assist in intervention measures from the government.

\subsection{Demographic/Family Profile}

Positive parenting in early childhood is one of the key contributors to healthy development of child (Dawson-McClure et al., 2015). However, poverty constrains parenting resources and jeopardizes successful development and self-regulation. Specific aspects of parenting are strongly linked to child development including support for positive behavior, behavior management and involvement in education. Interestingly, the National Health Interview Survey (NHIS) showed that while one-third of America's children had missed no school due to illness or injury in the previous 12 months, 4 percent missed 11 or more days, with a significant impact on their educational achievement. Children that lived in single mother headed households were found to be twice as likely as their peers to miss 11 or more days of school per year (Rosenbaum \& Blum, 2015).

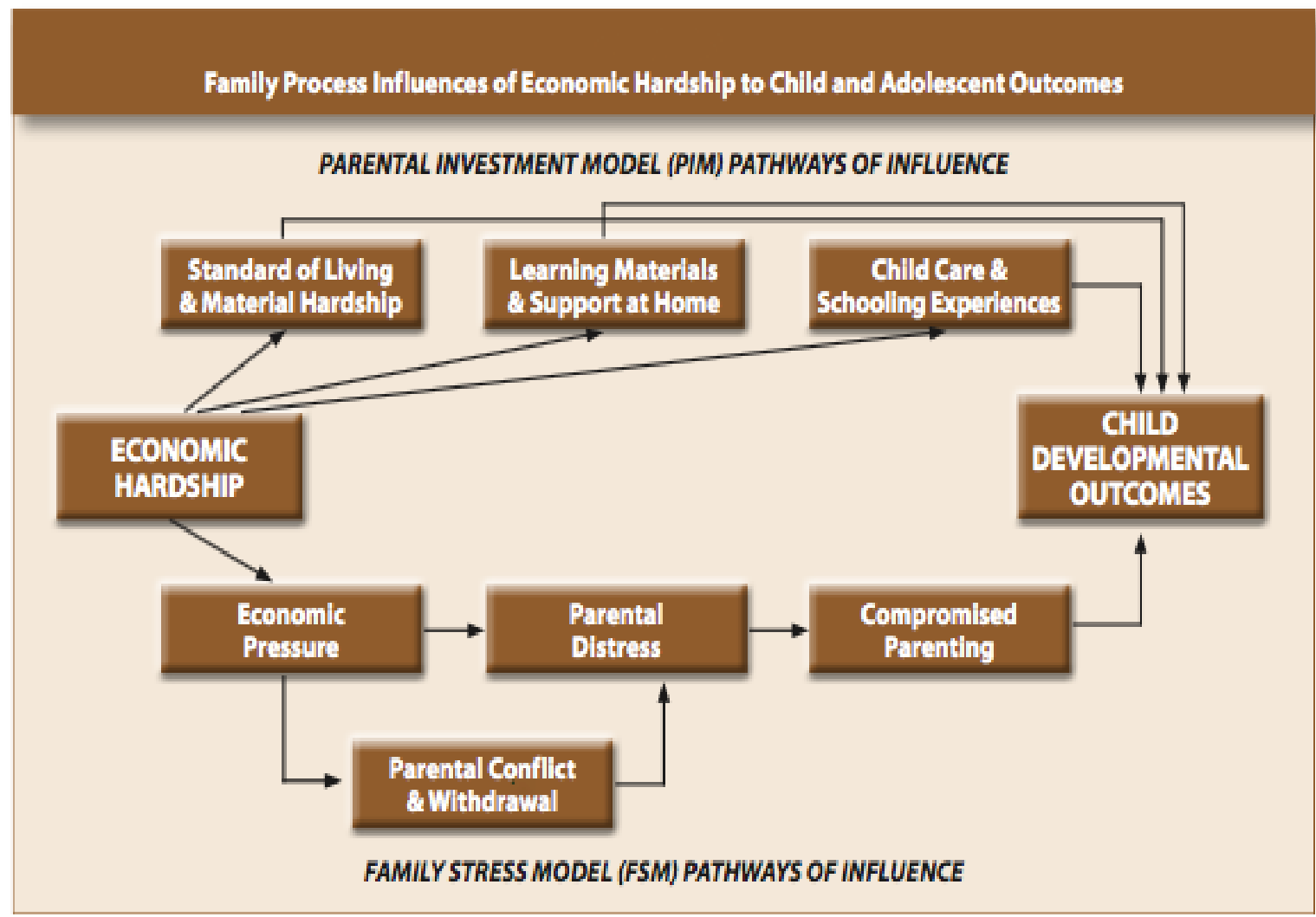

Figure 2. Parent Investment Model (PIM) and Family Stress Model (FSM)

(Diagram source: Mistry \& Wadsworth, 2011)

Parents are extremely instrumental in assisting children navigate through the school years (Mistry \& Wadsworth, 2011). Children often do better in academics when parents are involved and show interest in the child's schooling. Parental involvement includes parents' direct participation with teachers and other school staff. In addition, involvement consists of attending parent-teacher conferences, assisting child with homework, and establishing high expectations for the child. In the Parent Investment Model (PIM) depicted in the diagram above the economic hardship led to standard of living, maternal hardship and economic pressure, learning materials and support at home, and child care and schooling experiences. It is observed that economic pressures led to parental distress and compromised parenting. In addition, parental conflict and withdrawal was a result of economic pressure and parental conflict and withdrawal led to parental distress, which in turn compromised 
parenting practices. This influence was termed as Family Stress Model (FSM). As a result of PIM and FSM, and along with each of the factors listed therein, the context resulted in influencing child and adolescent developmental outcomes (Mistry \& Wadsworth, 2011).

\subsection{Labor Market, Income, and Economic Status}

The Eurochild reports that children at risk of poverty typically come from single-parent families, large families, families with unemployed parents, immigrant and ethnic minority families, and families having children with disabilities (Butiu, 2014). The report also stated that $19 \%$ of all children are at risk of poverty, $15 \%$ are leaving the educational system before high-school graduation, and the unemployment rate of the young is almost double the average rate. According to the United States national census data, $21.9 \%$ of all children under the age of 18 lived in poverty in 2011 (Luther, 2012). In 2010, 55\% of children living in poor or lowincome families had at least one parent who worked full time throughout the year. More than 16 million children were represented in this statistic, and approximately 2.8 million of these children lived in extreme poverty (U.S. Census Bureau, 2011). The current poverty line for the 48 contiguous states and the District of Columbia is $\$ 23,050$ for a family of four. With the cost of living continuing to increase, families are finding it difficult to obtain their necessities and adults find themselves in financial distress.

\subsection{Organizational Policy}

Among other structural circumstances, homelessness is often related to lower income levels. Reasons for homelessness are wide-ranging and complicated however, these reasons together result in over 600,000 individuals identified as homeless (Grineski, 2014; Hinton \& Cassel, 2013; Mistry \& Wadsworth, 2011). Grineski suggested that there is a lack of attention in regards to the tragic plight of more than 1.5 million children without homes. The lack of attention makes living in America an exhausting struggle for the many children who are categorized in the poorest sub-group whom lack adequate food, healthcare and stable housing. Further, children who are homeless have are the fastest growing segment of the homeless population for nearly 25 years. There are several challenges in which children face due to homelessness: physical and health problems, social problems, insecurities, trauma, and psychological stressors (Grineski, 2014; Herman, Bi, Border, \& Reinke, 2012; Hinton \& Cassel, 2013; Mistry \& Wadsworth, 2011; Tampubolon, 2015). In addition, poverty is intertwined with a large number of other co-factors, such as immigration, substance abuse, political unrest, incarceration, etc. The primary one, immigration is discussed here.

\subsubsection{Immigration}

Immigrant status is an important factor to consider in regards to understanding achievement among minority groups (Calzada, et al, 2015). There is a vast growing portion of the United States population since the year 2000. According to Borjas (2010), a crucial first step in studying immigrants and immigrant children is firstly defining the term "immigrant child." The most common definition used in research is those who are foreign-born and migrate to the United States with their foreign-born parents and those who are US-born to one or two immigrant (foreign-born) parents. There are a vast number of immigrant children, nearly $80 \%$ that are in fact, born in the United States. There has not been much research exploring whether childhood poverty affects native and immigrant children. According to Borjas, poverty could potentially have different consequences for immigrant and native children. Exposure to a disadvantaged background can imply different things for different groups of children, particularly because the immigrant experience introduces distant factors such as temporary family separation resulting from the vagaries of immigration law. The socioeconomic background of the household in which immigrant children are raised is likely to have a lasting influence on a wide array of outcomes as these children grow older, complete their education, and enter the labor market (Rosenbaum \& Blum, 2015). The neighborhood in which a child is born and grows up can have an important impact on the risk of illness or death as well as life expectancy.

Children with immigrant parents are typically represented among the population living in poverty (Mendoza, et al, 2017). In the United States at least half of Latino children have at least one parent who is immigrant. In the study by Mendoza et al., the association between economic hardship, immigration stress, and cortisol values were examined. The findings suggest that the highest cortisol values were found for children with parents with low acculturation levels and high economic hardship. However, for children with hardship (both high and low) and parents who reported higher levels of acculturation to English language use and U.S culture had low cortisol levels. The authors further found that the effects of economic hardship on the well-being of young children of Latino immigrants may very well depend on experiences in which are occurring simultaneously regarding sociocultural stresses with damaging effects surfacing for the outcomes when economic and sociocultural stressors are high.

Besides Latinos, about $12 \%$ of black children in the United States have immigrant parents (Calzada, et al, 2015). However, for black children with immigrant parents, studies have shown that they are more likely to 
succeed more than their peers even when faced with financial disadvantages. The researchers examined the relationship between school readiness skills and achievement from pre-kindergarten through the end of second grade in low-income black students with immigrant and US-born parents. The results found that children with immigrant and non-immigrant families, academic readiness scores were associated with reading and math scores; in addition, the same association was stronger among children from non-immigrant families. Students from non-immigrant families who enter school with higher levels of externalizing problems showed substantial deficits in reading and math. The findings also showed that black children from immigrant families are especially susceptible to specific risk factors that influence their academic performance. However, recent research investigated the early childhood development among black children of immigrant parents relative to children of other immigrant groups and black children born to US-born parents. At the age of two, children of black immigrants scored lower on a test of cognitive functioning compared to many of their peer groups. Black children of immigrants achieved more in reading and math, outperforming black children of US-born parents and Latino children from immigrant and non-immigrant families (Calzada et al., 2015).

\section{THEORETICAL FRAMEWORK}

There are several theories which help further clarify the relationship between children and poverty. Three theories that particularly assist in explaining this relation are: the ecocultural theory, the life course theory and the ecological systems theory. A brief encounter of the theoretical perspectives on the topic of children living in poverty is expounded below. The life course theory focuses on the developmental changes that occur in an individual at the intersection of the person's age/cohort with secular or historical events. As successive cohorts encounter the same historical event(s), they do so at different points in their life (Crivello \& Boyden, 2014). The life course theory assists in understanding the influence of poverty during childhood by focusing on relationships, order of life events, and influences of society. The theory assists in illustrating how poverty is measured in different stages of childhood, adolescence, and adulthood.

The ecocultural theory on the other hand, considers the ecological and cultural environment in which developmental processes are embedded (Mcwayne, Melzi, Limlingan, \& Schick, 2016). The theory highlights the interplay between individual-level processes and the socio-contextual conditions that influence such processes. This theory presupposes that families organize daily routines and activities according to cultural values, available economic and social resources, community norms, and contextual demands. The ecocultural theory assists in identifying protective factors that mitigate the risks and bolster skills that are essential to successful transition in school throughout childhood, especially in regards to low-income families.

Bronfenbrenner proposed an ecological systems theory of the lifelong progressive accommodations individuals make to changing environments in which they develop. Developmental outcomes are influenced by interactions within microsystems, or immediate settings that contain the developing person. The remaining structures that have developing influences include the mesosystem (processes among two or more microsystems; both contain the developing person), exosystem (processes between two or more settings; only one contains the developing person), macrosystem (influences of broader cultural and socioeconomic environment), and lastly chronosystem (effects of consistency and change over the life course). Bronfenbrenner's process-person-context-time (PPCT) model (Eamon, 2001) is used to examine theories that explain the adverse effects of economic deprivation on children's development. The process by which economic deprivation affects children's socioemotional deprivation is complex. However, given the multiple paths by which poverty can affect the socioemotional development of children, an ecological systems model provides appropriate intervention for families and children experiencing poverty and hindering in regards to socioemotional development. Similarly, according to Mendoza et al. (2017), Bronfenbrenner's ecological systems theory proposes that economic and sociocultural factors (economic hardship, immigrant stress interactions) influence the child in many ways.

Additionally, Blumer and the symbolic interactionism theory assist in explaining poverty by examining the individuals' interactions and gaining an understanding of their every day lives and routines. The theory examines the differences that stratification or the classification of individuals into groups, makes for lifestyle and interaction with others. Through a symbolic interactionism perspective, stratification impacts and furthermore affects the individual's lifestyle, interactions, beliefs and concepts of themselves (University of Minnesota Library, 2017). Through theoretical lenses, an individual can gain a better understanding of poverty and the impact that it has on individuals during lifespan, specifically during the childhood years. Each theory discussed is relevant to poverty; however each theory focuses on different aspects of poverty from alternative standpoints. It is important that various perspectives are considered for a comprehensive understanding of children living in poverty.

\section{IMPACT ON PHYSICAL DEVELOPMENT}


It can be assumed for the obvious reasons that compared with non-poor children; children experiencing poverty in the United States experience diminished physical health as measured by a number of indicators of health status and outcomes (Brooks-Gunn \& Duncan, 1997). Their research showed that children in poverty were only two-thirds as likely to be in fair or poor health as non-poor children. Serious disabilities, grade repetition and learning disabilities are most prevalent among children who were low birth weight as infants, as lower levels of intelligence and of math and reading achievement. It was further found that low birth rate, which is popular in families living in poverty, is a key risk factor for infant mortality, especially in regards to the first twenty-eight days of life. Structured activities serve as a protective function for youth living in poverty and for youth of color by buffering the negative effects of deviant peers and dangerous neighborhoods and providing safe, adult-supervised environments (Epps, Houston, \& Bobbitt, 2013).

Research has shown that child self-regulation to be adversely affected by disruptive and stressful environmental characteristics such as household and instability ad neighborhood poverty (Roy, McCoy, \& Raver, 2014; Snell, Castells, Duncan, Gennetian, \& Magnuson, 2013). According to Snell et al. (2013), the risks that children face due to environment may systematically differ by gender; boys may be particularly vulnerable in neighborhood of poverty because of the prevalence of gangs, drugs and violence as opposed to girls. Child's outdoor play is an important indicator of overall healthy development (Kimbro \& Schachter, 2011). Child's participation in structured activities has benefits in a variety of developmental domains including higher reading achievement, lower levels of aggression, and smaller increases in body mass index (Epps, et al). More specifically, urban, African-American adolescents who participated in structured activities had the highest levels of motivated engagement and confidence as well as low levels of alienation. In addition, within low-income families, adolescents who increased their structured activity participation as their mothers transitioned out of welfare also reported reduced delinquent behaviors.

Exploring brain growth and development of memory, several variations were noted among the children living in poverty. Working memory, which is a temporary storage mechanism, enables human beings to retain a limited amount of information for a short period of time. Evans \& Fuller-Rowell (2013) found drastic differences resulting due to living conditions. This temporary short-term storage is necessary for information to be encoded into long-term memory and thus is critical for such basic skills as language, reading, and problem solving. Working memory along with language were the most sensitive neuro-cognitive systems in relation to early deprivation. Not only does childhood disadvantage influence concurrent working memory, early childhood poverty predicts deficits in working memory capacity.

On the contrary, although chronic stress and poverty appear to degrade working memory, there are reasons to believe that other processes might come into the account (Evans \& Fuller-Rowell, 2013). Some individuals may be more resilient to the harmful effect of poverty, and thus not allow low-SES children would be expected to develop working memory deficits to the same extent. One component of resilience to poverty's ill effects on cognitive capacities such as working memory is self-regulatory skills. Self-regulation enables individuals to maintain emotional and behavioral self-control necessary for goal directed behavior in the face of competing social or physical demands (Evans \& Fuller-Rowell, 2013). Children appear to mature and grow with less ability to direct their attention away from competing social and environmental demands. They are hence, more vulnerable to stimulus bound demands from the external environment. Although brain development is discussed under the physical development, it forms the core part of cognitive abilities.

\section{IMPACT ON COGNITIVE DEVELOPMENT}

Research thus far has shown evidence confirming the influences of impoverished contexts on the cognitive performance at home and school. From a developmental cognitive neuroscience perspective, cognition is viewed as component codes, computed in different ways, and programmed to perform complex tasks, leading to new ways of thinking about how our brain organizes thought and emotional processes (Lipina et al., 2013). Specifically, processes involved in early cognitive control development, such as the different attention, working memory, and planning subsystems, are fundamental to cognition and social behavior throughout the lifespan in most cultures around the world. This section will address two main areas of understanding the impact on cognitive development, school achievement outcomes and behavioral outcomes.

\subsection{School Achievement Outcomes}

Poverty exacerbates problems for children with both developmental disorders due to accumulation of risk they experience (Flouri, Midouhas, Charman, \& Sarmadi, 2015; Luther, 2012; Mohan \& Shields, 2014). Current research shows that there is a large gap in the abilities of children from low-income and middle class families. Poverty is one of the most significant factors placing children at risk for school failure. "Instructing any young child to become a fluent reader can be a daunting task, but this is especially true when the student being taught has limited access to appropriate learning tools" (Luther, 2012, p. 36). While there is no doubt that poverty can greatly affect school performance and can make a tremendous impact on learning, it is also 
important to remember that poverty can also hinder later success in life. In a nutshell, Grineski (2014) comment that educational success is a life-altering outcome shaped by homelessness.

Continuing with the concept of income-achievement gap in children, it was found that children from lower-income households arrive at school behind in reading and math (Evans \& Fuller-Rowell, 2013). These gaps persist as children matriculate, leading to an increasing number in school dropout rates for lower-income children as well as lower earnings in adulthood. Children growing up in poverty have elevated chronic stress and worse working memory as young adults. According to several neuroscientists who have explored the role of the brain as a vexing social problem and as a result, one potentially critical neuro-cognitive process implicated in the income-achievement gap is working memory. Overall, it was observed that the poor children are less healthy; they often lack in specific areas, intellectually and socially (Kindg, 2016; Luby, et al., 2013). "Poverty was associated with smaller white and cortical gray matter and hippocampal and amygdala volumes. The effects of poverty on hippocampal volume were mediated by caregiving support/hostility on the left and right as well as stressful life events on the left" (Luby, et al., p. 1135). In addition, research has found that they are less likely to graduate from high school and are more likely to remain poor into parenthood themselves.

\subsection{Behavioral Outcomes}

Developmental circumstances such as poverty are thought to impede the ability of the child to achieve developmental milestones in the cognitive and socio-emotional domains (Jensen, Dumontheil \& Barker, 2014). Research has shown that poverty negatively impacts a range of cognitive functions and social abilities as well as the child's ability to regulate their own emotions and behaviors. According to Lipina et al. (2013), in a behavioral study on infants, preschoolers, first graders, and middle school children, low socioeconomic status children reduced performance compared to middle socioeconomic status children. Findings such as these suggest that there is a link between income and basic needs in relation to poverty, and that it is associated with social inequalities in early experience of life (Lipina et al., 2013).

Contextual risks are factors that affect an individual's basic living conditions; examples of contextual risk factors are poverty, finances and scarce resources (Jensen, et al, 2014). The effect of contextual risks on child cognitive functioning is believed to work through parents whom have lower levels of education and limited resources to engage their children in cognitively stimulating interactions. In addition, factors related to parental education and economic resources have previously been associated with below average language development in children. In addition, Jensen, et al found that maternal depression as a result of poverty, can negatively impact the child's cognitive functioning, including executive functions such as attention, inhibitory control, IQ, and language development.

\section{IMPACT ON SOCIOEMOTIONAL DEVELOPMENT}

The social development during childhood such as friend-group identification and development of autonomy are decisively affected by poverty. This is one of the main reasons why the child welfare shows up more and more frequently in public policy debates and thus leaving open the question of the role of governments as social actors. The economic welfare of the child is affected evidently by the family income and thus poverty becomes determined by the family's poverty. In regards to socio-emotional development, childhood poverty and social exclusion have a significant impact on child development (Butiu, 2014).

A broader concept than poverty is that of social exclusion, because it expresses not just the lack of material means, but also the difficulty of being connected to social networks. In order words, it signifies not just the deficit of income or of consumption, but also of participation to everyday lifestyle or to social activities Socioemotional problems consist of problematic peer relations and disruptive classroom behaviors (Eamon, 2001). Developmentalists explain that the infants innately recognize only six basic emotions: joy, anger, surprise, disgust, sadness, and fear (Jensen et al, 2014). Other emotions, like respect and compassion, must be taught and experienced through their relationships with others. If these are not being taught or experienced, behavior problems in school are likely to occur.

According to Eamon (2001), Bronfenbrenner's PPCT (process-person-context-time) model is used to examine the adverse effects of economic deprivation on children's socioemotional development. The PPCT Model has four major concepts consisting of process, person, context and time (Krishnan, 2010). Firstly, the 'process' involves the transactions between the child and the child's surroundings, in which are responsible for the child's performance, survival and overall wellbeing. Next, the 'person' involves the influence of individuals in the child's social environment on growth and development; this can consist of family, peers and caregivers. The 'context' concept involves the environments in which the child has constant interaction. This can consist of physical, social and even economic interaction and varies depending on concentric systems (micro, meso, exo, macro, chrono). Lastly, the 'time' concept involves aspects such as age, duration and nature of periodicity. The time concept is important because when events occur, they impact development and over time, the impact decreases. In essence, Krishnan elaborates that PPCT model emphasizes that child is impacted by immediate 
surroundings as well as well as interactions with larger environment. People and contexts and interactions among them have a crucial impact on shaping the overall development of children.

\section{IMPACT DURING LATER YEARS}

According to Karageorge (2016) and reliable tax records, there are gender gaps in regards to whom was affected the most in regards to employment, income and college enrollment for adults ages 18-23. Gender differences in employment rates vary in regards to their parent's income. Karageorge's findings showed that employment rates increased with parental incomes for both genders and the increase was more pronounced for men. However, at the lowest income quintile, the trend was even more evident, with men experiencing lower rates of employment than women. Among people whose parents were in the bottom fifth (lower quintile) of income distribution when they were young, 30-year-old men were less likely to have a job than were the women. This was especially true among boys who were raised by a single parent. The effect of employment rates was most apparent among men raised in single-parent households. Men have higher earnings than women across the parent-income distribution, but the difference was less pronounced in the lowest income quintile. Men were also less likely to attend college compared with women across the parent-income distribution, with the greatest disparity observed among men from lower income families (Karageorge, 2016).

Besides the income or earnings, there is also a pattern of employment gender gap in regards to geographic areas (Karageorge, 2016). There were patterns across the commuting zones, which are clusters of counties or in other words, connected by transit. Studies showed that there were substantial differences among the geographical areas. The areas where men are less likely than women to have a job are those with a concentration of minority residents, single-parent households, and high racial segregation. The location in which there was a gap was primarily in New York (3\%), Charlotte (12\%), and North Carolina (12\%).

\section{CONCLUSIONS}

Overall, it can be recognized that poverty has a significant impact on individuals of all ages, but especially children in regards to physical, cognitive and socio-emotional development. The rate of poverty especially for children is increasing in degree of income inequality (Sachs, 2016). About 15 million children in the United States live in families with incomes below the federal poverty threshold. Children in the United States experience higher poverty rates than most nations and as result poverty impedes the child's ability to learn and impacts development, especially in regards to emotional, social and behavioral.

The effects that poverty often has on children are both direct and indirect (National Center for Children in Poverty, 2017; Yoshikawa, et al, 2012). The consequences of such effects are cumulative and can possibly hinder children even at a later stage. Additionally, poverty varies geographically, depending on ethnicity, race and community. There is a need for intervention and further attention given in regards to the relation of poverty and children. Childhood poverty is a colossal concern in the world today that needs to be addressed for wholesome development of children and a brighter future. National Center for Children in Poverty has reiterated that living in impoverished conditions can impede children's capability to acquire knowledge and skills and contribute to social, emotional, and behavioral problems. Poverty also can contribute to poor health and mental health. Risks are greatest for children who experience poverty when they are young and/or experience deep and persistent poverty. The authors further suggest a few interventions during the early childhood stage with the outcomes of increases in income among parents in families receiving early childhood services and among the children up until their adult years.

Programs such as Nurse-Family Partnership, an intensive family support program for low-income first-time mothers. In addition, the Perry Preschool program, which consists of combining half-day preschool intervention for four-year-old children with, visits ever week home visits by preschool teachers (Yoshikawa, et al.). This program increased earnings, reduced likelihood of juvenile delinquency and adult crimes, and reduced likelihood of receiving welfare. The Women, Infants and Children Program, a program in which provides nutritional supplements are provided, and is known to improve birth outcomes and infant health, thus impacting behavioral outcomes has been the most popular one (Yoshikawa, et al). Lastly, Moving to Opportunity is a program in which offers vouchers to low-poverty neighborhoods. In addition, there are policies in which have been proven to reduce child poverty. For example, food stamps have been proven to reduce food insecurity and health insurance coverage for children improves health outcomes. Several programs like these and a few more that can reach various corners of poverty-struck population are a must for combating, and eventually, eradicating poverty conditions across the US and globally. "Research is clear that poverty is the single greatest threat to children's well-being. But, effective public policies - to make work pay for low-income parents and to provide high-quality early care and learning experiences for their children - can make a difference. Investments in the most vulnerable children are also critical" (National Center for Children in Poverty, 2017, para. 3). Being that poverty is such a massive threat to child development and wellbeing, it is important for scholars, policymakers and researchers to be aware, and furthermore to provide awareness to the public, as well as high quality care for low-income families and better experiences for children who suffer from poverty. 


\section{REFERENCES}

[1]. Kindig, D. A. (2015). Improving our children's health is an investment priority. The Milbank Quarterly, 93(9), 255-258.

[2]. Yoshikawa, H., Aber, L. J., \& Beardslee, W. R. (2012). Effects of poverty on the mental, emotional, and behavioral health of children and youth. American Psychologist, 67(4), 272-284.

[3]. Butiu, C. A. (2014). Childhood poverty and social exclusion: European approaches. Journal Plus Education, 10(2), 77-86.

[4]. Gradin, C., \& Canto, O. (2012). Why are child poverty rates so persistently high in Spain? The Manchester School, 80(1), 117-143.

[5]. Borjas, G. J. (2010). Poverty and program participation among immigrant children. The Future of Children, 21(1), 247-266.

[6]. Zalewski, M., Lengua, L. J., Fisher, P. A., Trancik, A., Bush, N. R., \& Meltzoff, A. N. (2012). Poverty and single parenting: Relations with preschoolers' cortisol and effortful control. Infant and Child Development, 21, 537-554.

[7]. Crivello, G., \& Boyden, J. (2014). On childhood and risk: An exploration of children's everyday experiences in rural Peru. Children \& Society, 28, 380-391.

[8]. Grineski, S. (2014). The multi-dimensional lives of children who are homeless. Critical Questions in Education, 5(3), 204-217.

[9]. Chen, W. H., \& Corak, M. (2008). Child poverty and changes in child poverty. Demography, 45(3), pp. 537-553.

[10]. ] Dawson-McClure, S., Calzada, E., Huang, K., Kamboukos, D., Rhule, D., Kolawole, B., Petkova, E., \& Brotman, L. M. (2015). A population-level approach to promoting healthy child development and school success in low-income, urban neighborhoods: Impact on parenting and child conduct problems. Prevention Science, 16, 279-290.

[11]. Rosenbaum, S., \& Blum, R. (2015). How healthy are our children? The Future of Children, 25(1), 11-34.

[12]. Mistry, R. S., \& Wadsworth, M. E. (2011). Family functioning and child development in the context of poverty. The Prevention Researcher, 18(4), 11-15.

[13]. Luther, V. (2012). The riches of literacy: Teaching reading skills to young children living in poverty. The California Reader, 46(1), 35-41.

[14]. United States Census Bureau. (2011). Income, poverty, and health insurance coverage in the United States: 2010. Current Population Reports, U.S. Department of Commerce, Author.

[15]. Hinton, S., \& Cassel, D. (2012). Exploring the lived experiences of homeless families with young children. Early Childhood Education, 41, 457-463.

[16]. Herman, K. C., Bi, Y., Borden, L. A., \& Reinke, W. M. (2012). Latent classes of psychiatric symptoms among Chinese children living in poverty. Journal of Child Family Studies, 21, 391-402.

[17]. Tampubolon, G. (2015). Growing up in poverty, growing old in infirmity: The long arm of childhood conditions in Great Britain. PLOS ONE, 10(12), 1-16.

[18]. Calzada, E., Barajas-Gonzalez, R. G., Dawson-McClure, S., Huang, K., Palamar, J., Kamboukos, D. \& Brotman, L. M. (2015). Early academic achievement among American low-income Black students from immigrant and non-immigrant families. Prevention Science, 16, 1159-1168.

[19]. Mendoza, M. M., Dmitrieva, J., Perreira, K. M., Hurwich-Reiss, E., \& Watamura, S. E. (2017). The effects of economic and sociocultural stressors on the well-being of children of Latino immigrants living in poverty. Cultural Diversity and Ethnic Minority Psychology, 23(1), 15-26.

[20]. McWayne, C. M., Melzi, G., Limlingan, M. C., \& Schick, A. (2016). Ecocultural patterns of family engagement among low-income Latino families of preschool children. Developmental Psychology, 52(7), 1088-1102.

[21]. Eamon, M. K. (2001). The effects of poverty on children's socioemotional development: An ecological systems analysis. Journal of Social Work, 46(3), 256-266.

[22]. University of Minnesota Library Publishing. (2017). Social Problems: Continuity and Change Explaining Poverty. Retrieved from http://open.lib.umn.edu/socialproblems/chapter/2-3-explainingpoverty/

[23]. Brooks-Gunn, J., \& Duncan, G. J. The effects of poverty. The Future of Children, 7(2), 55-71.

[24]. Epps, S. R., Huston, A. C., \& Bobbitt, K. C. (2013). Developmental changes in impacts of an antipoverty experiment on low-income children's structured out-of-school time. Developmental Psychology, 49(9), 1763-1774.

[25]. Roy, A. L., McCoy, D. C., \& Raver, C. C. (2014). Instability versus quality: Residential mobility, neighborhood poverty, and children's self-regulation. Developmental Psychology, 50(7), 1891-1896. 
[26]. Snell, E. K., Castell, N., Duncan. G., Gennetian, L., Magnuson, K., \& Morris, P. (2013). Promoting the positive development of boys in high-poverty neighborhoods: Evidence from four anti-poverty experiments. Journal of Research on Adolescence, 23(2), 357-374.

[27]. Kimbro, R. T., \& Schachter, A. (2011). Neighborhood poverty and maternal fears of children's outdoor play. Family Relations, 60, 461-475.

[28]. Evans, G. W., \& Fuller-Rowell, T. E. (2013). Childhood poverty, chronic stress, and young adult working memory: The protective role of self-regulatory capacity. Journal of Developmental Science, 16(5), 688696.

[29]. Lipina, S., Segretin, S., Hermida, J., Prats, L., Fracchia, C., Camelo, J. L., \& Colombo, J. (2013). Linking childhood poverty and cognition: Environmental mediators of non-verbal executive control in an Argentine sample. Journal of Developmental Science, 16(5), 697-707.

[30]. Flouri, E., Midouhas, E., Charman, T., \& Sarmadi, Z. (2015). Poverty and the growth of emotional and conduct problems in children with autism with and without comorbid ADHD. Journal of Autism Development Disorder, 45, 2928-2938.

[31]. Mohan, E., \& Shields, C. M. (2014). The voices behind the numbers: Understanding the experiences of homeless students. Critical Questions in Education, 5(3), 190-202.

[32]. Luby, J., Belden, A., Botteron, K., Marrus, N., Harms, M. P., Babb, C., Nishino, T., \& Barch, D. (2013). The effects of poverty on childhood brain development: The mediating effect of caregiving and stressful life events. Journal of American Medical Association Pediatrics, 167(12), 1135-1142.

[33]. Jensen, S. K. G., Dumontheil, I., \& Barker, E. D. (2014). Developmental inter-relations between early maternal depression, contextual risks, and interpersonal stress, and their effect on later child cognitive functioning. Depression and Anxiety, 31, 599-607.

[34]. Krishnan, V. (2010). Early child development: A conceptual model. Presented at the Early Childhood Council Annual Conference 2010, Christchurch, New Zealand, 7-9 May 2010.

[35]. Karageorge, E. (2016). Growing up in high-poverty areas can affect your employment. Monthly Labor Review, 139(3), 1-22.

[36]. Sachs, J. (September 30, 2016). The end of poverty by Jeffrey Sachs-A summary of chapters 1-4. Retrieved from https://revisesociology.com/2016/09/30/end-poverty-sachs-summary/

[37]. National Center for Children in Poverty. (2017). Child poverty. Retrieved from http://nccp.org/topics/childpoverty.html 